\title{
Tıbbi Uygulama Hatası Riski Yüksek Olan Uzmanlık Dallanının Tıpta Uzmanlık Sınavında Tercih Edilme Önceliklerinin Yıllara Göre Değişimi
}

\author{
The Change of Preference Prioritiies on Examination for Specialty in Medicine by Years of \\ High Risky Medical Branches in Medical Malpractice
}

\author{
Hüseyin Kasap ${ }^{1}$, Taner Akar ${ }^{1}$, Birol Demirel ${ }^{1}$, Ahmet Zahit Dursun ${ }^{1}$, Serhat Sarı ${ }^{1}$, Alper Özkök ${ }^{1}$, Önder Aydemir ${ }^{2}$ \\ ${ }^{1}$ Gazi Üniversitesi Tip Fakültesi Adli Tip Anabilim Dal, Ankara \\ ${ }^{2}$ Gazi Üniversitesi Tip Fakültesi Halk Sağlığı Anabilim Dalı, Ankara
}

\section{Özet}

Giriş-Amaç: Hekimlerin, hukuka aykırı ve/veya kusurlu tıbbi müdahale ve tedavilerinden dolayı hastalığın normal seyrinin dışına çıkması, iyileşmesinin gecikmesi, hastanın ölümüne neden olması tıbbi uygulama hatası olarak tanımlanmaktadır. Tibbi uygulama hatası iddiasıyla hekimlere karşı açılan gerek ceza gerekse tazminat davalarındaki artışlar, hekimleri defansif tıp uygulamaya yöneltmiştir. Defansif tıbbın, Tıpta Uzmanlık Sınavına yansıması ise; daha düşüik riskli uzmanlık dallarının öncelikle tercih edilmesi olmaktadır.

Gereç-Yöntem: Bu çalışmada, 2010 yılında yürürlüğe giren 'Tıbbi Kötü Uygulamaya İlişkin Zorunlu Mali Sorumluluk Sigortası' kapsamında risk grupları belirlenen uzmanlık dallarının, yıllar içerisinde hekimler tarafından tercih edilme önceliklerindeki değişimin gösterilmesi amaçlanmıştır. Bu sigorta kapsamında, risk düzeyi en yüksek 4. grup, en düşük risk grubu ise 1. grup olarak belirlenmiştir.

Bulgular: 2009-2013 yılları arasındaki Tıpta Uzmanlık Sınavı (TUS) yerleştirme sonuçlarına göre uzmanlık dallarının ülke genelindeki taban puanları, çalışmaya dahil edilmiştir. 2009'dan 2013'e gelinen süreçte, 2. grubun taban puanlarının giderek arttığı, 3. grubun sabit kaldığı, 4. grubun ise anlamlı derecede düştüğü saptanmıştır.

Sonuç: Hekimlerin önceliklerinin değişmesinde, son yıllarda hekime yönelik şiddet olaylarındaki artışın yanı sıra, tıbbi uygulama hataları riskinin diğer gruplara göre daha yüksek olması, dolayısıyla açılan dava sayılarının ve hükmedilen tazminat miktarlarının giderek artmasına karşın hekimlerin aldıkları riskle orantılı olarak kazançlarının artmaması olduğu kanaatine varılmıştır. Hekimler arasında defansif tıp uygulamalarının gün geçtikçe arttı̆̆ı tartışılırken, yapılan bu çalışmada bu durumun uzman hekim adaylarının tercihlerine bile yansıdığı görülmektedir.

Anahtar kelimeler: Tibbi uygulama hatası, Defansif tıp, Tipta uzmanlık sinavı.

\section{Abstract}

Objective: Malpractice is defined as the illness going out of its normal course, delayed healing, death of a patient because of physicians unlawful and/or defective medical practice and treatment. The increase in the both criminal and compensation cases claiming malpractice have led the physicians to practice defensive medicine. Defensive medicine's reflection to the "Examination for Specialty in Medicine" is that specialties with lower risk are preferred priorly.

Materilals and Methods: In this research it is aimed to demonstrate the change of preference priorities of specialties by physicians after the risk groups were determined relying on the 'Compulsory Liability Insurance Related to Medical Malpractice', entered into force in 2010. According to this insurance, the group with the highest risk is 4 th and the group with the lowest risk is the 1st. The base points of specialties according to 2009-2013 Examination for Specialty in Medicine (TUS) placement results were included to the research.

Results: From 2009 to 2013 it was determined that second group's base points increased gradually, third group remained stable and the fourth group decreased significantly.

Conclusion: We believe that, the reason of the change of the priority of physicians is not only the rise of the violence of which the physicians are subjected to, but also, in spite of the increased number of claims braught and the amount of indemnity due to the higher risk of the medical application faults compared to other groups, the almost steady income of the physicians compared with that risks that take. While it is being discussed that defensive medicine is practiced more often each day, we demonstrated in this research that this situation is even reflected to the preferences of specialist candidates.

Keywords: Medical malpractice, Defensive medicine, Examination for specialty in medicine.

\section{Giriş}

Hekimlerin, hukuka aykırı ve/veya kusurlu tıbbi müdahale ve tedavilerinden dolayı hastalığın normal seyrinin dışına ç1kması, iyileşmesinin gecikmesi, hastanın ölümüne neden olması tıbbi uygulama hatası olarak tanımlanmaktadır(1). Günümüzde 2005 y1lından bu yana yürürlükte olan Türk Ceza

Sorumlu Yazar: Hüseyin KASAP

Gazi Üniversitesi Tip Fakültesi Adli Tip Anabilim Dal, Ankara

E-mail: doktorkasap@gmail.com

Geliş: 14.11.2014

Düzeltme: 19.02.2015

Kabul: 20.02.2015
Kanunu'nda, eskisine nazaran tıbbi uygulama hataları nedeni ile hekimleri ilgilendiren ceza oranlarının yüksekliğinin yanı sıra, hekimlere karşı açılan gerek ceza gerekse tazminat davalarındaki artışlar, hekimleri defansif tıp uygulamaya yöneltmiştir. Defansif tıp, olası bir tıbbi uygulama hatası suçlamasıyla karşılaşmamak için hekimlerin daha fazla yardımcı tanı yöntemi kullanması olarak tanımlanmaktadır(2). Defansif tıbbın, Tipta Uzmanlık Sinavı'na (TUS) yansıması ise; daha düşük riskli uzmanlık dallarının öncelikle tercih edilmesi 
olmaktadir.

Bu çalışmada, 2010 yılında yürürlüğe giren Tıbbi Kötü Uygulamaya İlişkin Zorunlu Mali Sorumluluk Sigortası(3) kapsamında yüksek riskli olarak belirlenen ve literatürde dava edilme riskinin yüksek olduğu ifade edilen uzmanlık dallarının, yıllar içerisinde hekimler tarafından tercih edilme önceliklerindeki değişimin tespit edilmesi amaçlanmıştır.

\section{Gereç ve Yöntem}

Tibbi Kötü Uygulamaya İlişkin Zorunlu Mali Sorumluluk Sigortası kapsamında, 2, 3 ve 4. grup olarak belirlenen uzmanlık dallarının, 2009-2013 yılları arasında TUS yerleştirme sonuçlarına göre ülke genelindeki taban puanlarına, Ölçme, Seçme ve Yerleştirme Merkezi'nin resmi internet sitesinden ulaşılmış, elde edilen veriler SPSS for Windows 22.0 istatistik programına aktarılarak analiz edilmiştir. Risk grupları arasındaki karşılaştırmalar, normal dağılıma uygunluğu kontrol edildikten sonra Kruskal Wallis testi ile, saptanan farkın kaynağını bulmak üzere yapılan ikili karşılaştırmalar ise post-hoc Bonferroni düzeltmeli Mann Whitney U testi ile yapılmıştır. İstatistiksel anlamlılık düzeyi $\mathrm{p}<0.05$ alınmıştır. Risk Grupları içine 2. Grupta; Aile Hekimliği, Dermatoloji, Fiziksel Tip ve Rehabilitasyon, Nükleer Tip, Radyasyon Onkolojisi, Spor Hekimliği, Sualtı Hekimliği ve Hiperbarik Tıp, Tıbbi Genetik, 3.Grupta; Çocuk Cerrahisi, Çocuk Psikiyatrisi, Enfeksiyon Hastalıkları, Göğüs Hastalıkları, Göz Hastalıkları, İç Hastalıkları, Kardiyoloji, Kulak Burun Boğaz Hastalıkları, Nöroloji, Radyoloji, Psikiyatri, Üroloji, 4.Grupta; Acil Tıp, Anesteziyoloji ve Reanimasyon, Beyin ve Sinir Cerrahisi, Genel Cerrahi, Göğüs Cerrahisi, Kadın Hastalıkları ve Doğum, KalpDamar Cerrahisi, Ortopedi ve Travmatoloji, Plastik ve Rekonstrüktif Cerrahi uzmanlık dalları çalışmaya dahil edilmiștir. 1. Grubu oluşturan; Adli Tıp, Anatomi, Fizyoloji, Halk Sağlığı, Histoloji ve Embriyoloji, Tıbbi Biyokimya, Tıbbi Ekoloji ve Hidroklimatoloji, Tıbbi Farmakoloji, Tıbbi Mikrobiyoloji, Tıbbi Patoloji uzmanlık dallarının büyük kısmının Temel Bilimler alanındaki uzmanlık dalları olması, bu alanlarda tıbbi uygulama hatası riski ile karşılaşma ve dava edilme ihtimalinin düşük olması nedeniyle 1. Grup, çalışmaya dahil edilmemiştir.

\section{Bulgular}

2009-2013 yılları arasındaki beş yıllık süreçte, yılda iki kez yapilan [ilkbahar (1) ve sonbahar (2)] toplam 10 TUS'un taban puanları incelenmiş, 2., 3. ve 4. grupta yer alan uzmanlık dallarının taban puanları arasında istatistiksel olarak anlamlı fark saptanmıştır. 4. grubun taban puanları diğer gruplara göre anlamlı derecede daha düşüktür $(\mathrm{p}<0.05)$.

2009'dan 2013'e gelinen süreçte, 2. grubun taban puanlarının giderek arttığı, 3. grubun sabit kaldığı, 4. grubun ise anlamlı derecede düştüğü saptanmıştır (Grafik 1).

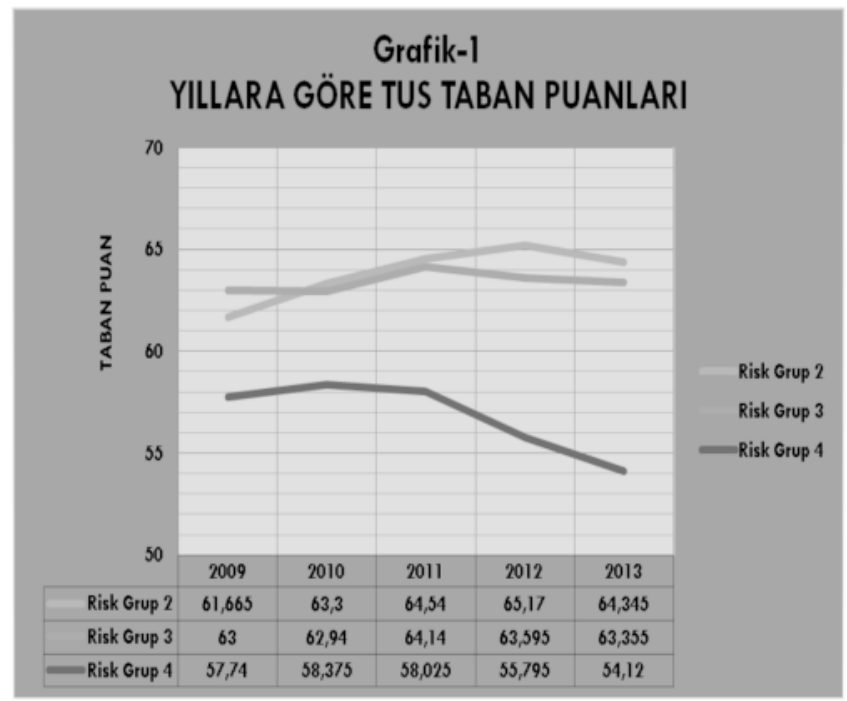

Grafik 1. Risk grubu 2,3 ve 4'ün TUS taban puanlarının yıllara göre değişimi.

4. grupta yer alan Acil Tip, Anesteziyoloji ve Reanimasyon, Beyin ve Sinir Cerrahisi, Genel Cerrahi, Göğuis Cerrahisi, Kadın Hastalıkları ve Doğum, Kalp-Damar Cerrahisi, Ortopedi ve Travmatoloji, Plastik ve Rekonstrüktif Cerrahi uzmanlık dallarının TUS taban puanlarının yıllara göre değişimi Grafik 2'de verilmiştir.

Literatürde dava edilme risklerinin yüksek olduğu belirtilen uzmanlık dallarının(4) TUS taban puanlarının yıllara göre değişimi Grafik 3’te gösterilmiştir.

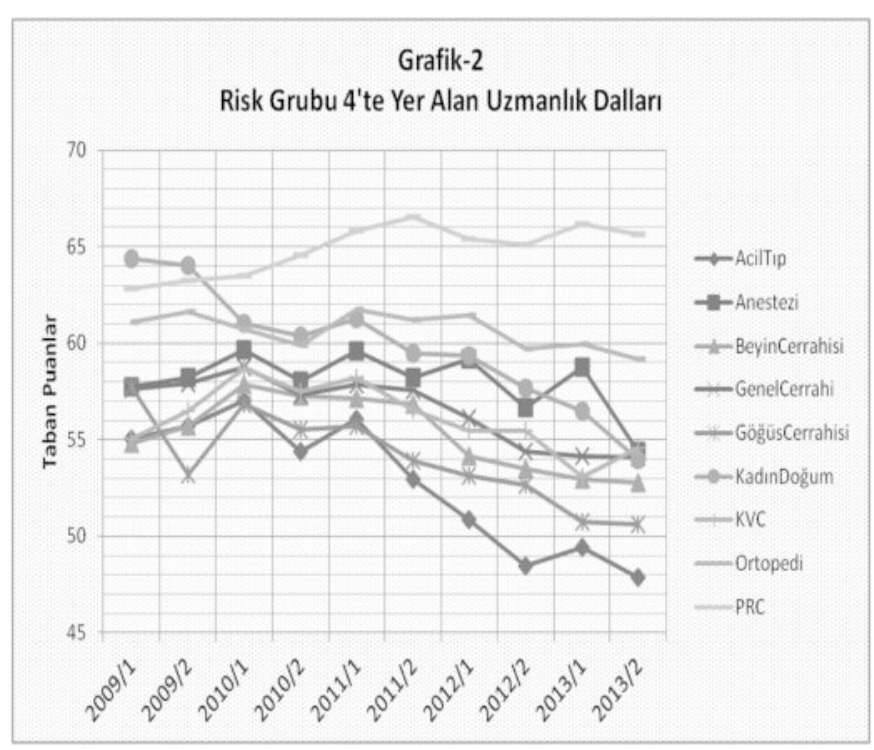

Grafik 2. Risk grubu 4’te yer alan uzmanlık dalların taban puanlarının yıllara göre değişimi. 


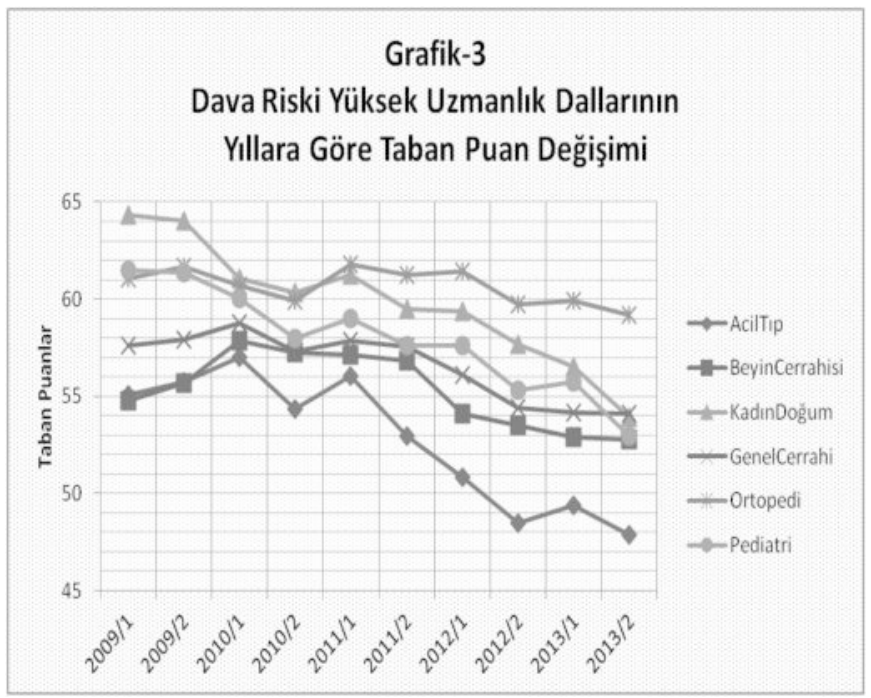

Grafik 3. Literatürde dava edilme riski en yüksek 6 uzmanlık dalının yıllara taban puanlarının değişimi.

\section{Tartışma ve Sonuç}

Hekimlerin, 4. grupta yer alan uzmanlık dalların giderek daha az tercih etmelerinin başlica nedenlerinin, son yıllarda hekime yönelik şiddet olaylarındaki artışı hekimleri klinik dışı branşlara yöneltmesinin yanı sıra, tıbbi uygulama hataları riskinin diğer gruplara göre daha yüksek olması, dolayısıyla açılan dava sayılarının ve hükmedilen tazminat miktarlarının giderek artmasına karşın, hekimlerin aldıkları riskle orantılı olarak kazançlarının artmaması olduğu düşünülebilir.

Can'ın çalışmasında Yargıtay'da karara bağlanan tıbbi uygulama hatası iddialarına konu olan girişimlerin, kliniklere göre dağılımı incelendiğinde en fazla Genel Cerrahi alanının dava edildiği, bunu Kadın Hastalıkları ve Doğum, Ortopedi ve Travmatoloji, Anesteziyoloji ve Reanimasyon, Kulak Burun Boğaz Hastalıklarının izlediği belirtilmiştir (5). Yılmaz'ın çalışmasında ise cerrahi uzmanlık dalları içerisinde, Genel Cerrahi, Kadın Hastalıkları Doğum ve Beyin ve Sinir Cerrahi uzmanlık dallarının istatistiksel olarak anlamlı şekilde daha çok dava edildiğinin gözlendiği belirtilmiştir(6). Pakiş’in çalışmasında dava riski yüksek ilk altı uzmanlık dalının sırasıyla Acil Tıp, Kadın Hastalıkları ve Doğum, Genel Cerrahi, Çocuk Hastalıkları, Beyin ve Sinir Cerrahisi ve Ortopedi ve Travmatoloji olarak belirtilmiştir (7).

Defansif tıp uygulamalarının gerçekleştirilmesindeki en güçlü etkenin dava edilme korkusu olduğu bilinmektedir(4). Hekimler arasında defansif tıp uygulamalarının gün geçtikçe arttığı tartışılırken, yapılan bu çalışmada bu durumun uzman hekim adaylarının tercihlerine bile yansıdığı görülmektedir. Budakoğlu ve arkadaşlarının 2011-2012 yıllarında son sınıf tıp öğrencilerine yapmış olduğu bir araştırmada; önceki yıllarda daha sıklıkla tercih edilen uzmanlık dalları; Plastik ve
Rekonstrüktif Cerrahi, Genel Cerrahi, Kalp ve Damar Cerrahisi, Pediatri iken, şimdilerde ise daha öncelikli tercih edilen dalların, tıbbi uygulama hatası olasılığı açısından daha az riskli olan, Dermatoloji, Psikiyatri, Radyoloji olduğu belirtilmiştir. Söz konusu çalışmada erkek öğrenciler; Radyoloji, Kulak Burun Boğaz Hastalıkları ve Psikiyatriyi, kız öğrenciler ise; Dermatoloji ve Göz Hastalıkları uzmanlık dallarını, öncelikli olarak tercih etmiştir. Özellikle, son birkaç yılda artan tıbbi uygulama hatası iddiası nedeniyle açılan davaların, öğrencilerin daha az riskli branşları tercih etmesinin önemli bir faktör olduğu vurgulanmıştır (8). Bu çalışmada da; TUS’ta önceleri daha yüksek puanlarla tercih edilen yüksek riskli uzmanlık dallarının tercih edilme öncelikleri, daha az riskli olan diğer uzmanlık dalları ile ve temel bilimler uzmanlık dalları ile yer değiştirmektedir. Uzmanlık dalı tercihinde değişime sebep olan bu durumun, yüksek riskli uzmanlık dallarında halen çalışmakta olan hekimleri de etkilediğini gösteren Tan'ın çalışmasında, temel bilimlerde çalışan hekimlerin genel ve dışsal iş doyum puan ortalamaları dahili ve cerrahi bilim dallarında çalışan hekimlere göre anlamlı bir şekilde daha yüksek bulunduğu görülmüş, iş doyumunun yüksekliğine paralel olarak TUS’ta da temel bilim dallarının puanının giderek yüksseldiği belirtilmiştir (9). Yapılan bir başka araştırmada da, 2007-2013 yılları arasında hekimlerin branş tercihlerindeki değişimler, 13 adet TUS kadro ve puanları incelenerek yıllara ve alanlara göre analiz edildiği, Sağlıkta Dönüşüm Projesi, Tam Gün Yasası ve hatalı tıbbi uygulama davalarının ve cezaların artması gibi çeşitli faktörlerin etkisiyle hekimlerin TUS tercihleri değişmeye başladığı, tıbbi biyokimya ve tıbbi mikrobiyoloji puanlarında yükselme görülürken, kadın hastalıkları ve doğum, genel cerrahi ve çocuk sağlığ 1 ve hastalıkları branşlarının taban puanlarında belirgin düşüşler olduğu belirtilmiştir (10).

En yüksek riskli grup olarak adlandırılan 4. gruptaki uzmanlık dallarının taban puanlarının, incelediğimiz son 5 yılda anlamlı derecede düşmesi, bu düşüşünün devam edeceğini düşündürmektedir. Her ne kadar TUS’ta alınan puanın nitelikli ve iyi hekimlikle birebir ilişkisi olmasa da uzman hekim adaylarının önceliklerini göstermektedir. Gerekli görülen önlemlerin araştırılıp bir an önce bu önlemlerin alınmaması durumunda, yüksek riskli branşların tercih önceliği giderek gerileyecek, ciddi emek ve bilgi birikimi gerektiren, hayati öneme sahip bu uzmanlık dallarını arzu edilmeyen uzmanlık dalları konumuna getirecektir.

\section{Kaynaklar}

1. Çetin G. Tibbi Malpraktis. Yeni Yasalar Çerçevesinde Hekimlerin Hukuki ve Cezai Sorumluluğu, Tibbi Malpraktis ve Adli Raporların Düzenlenmesi, Cerrahpaşa Tip Fakültesi Sürekli Tıp Eğitimi Etkinlikleri Sempozyum Dizisi No:48 kitabı içinde Ed: Çetin G, Yorulmaz C, Cerrahpaşa Yayınları, İstanbul 2006; 31-42. 
2. Aynacı Y. Hekimlerde defansif (çekinik) tıp uygulamalarının araştırılması. Selçuk Üniversitesi Meram Tip Fakültesi Adli Tıp Anabilim Dalı, Uzmanlık Tezi, Konya, 2008.

3. Tıbbi Kötü Uygulamaya İlişkin Zorunlu Mali Sorumluluk Sigortasında Kurum Katkısına İlişkin Usul Ve Esaslara Dair Tebliğ, Resmi Gazete: 21 Temmuz 2010, Sayı: 27648

4. Studdert DM, Mello MM, Sage WM, DesRoches CM, Peugh J, Zapert K, Brennan TA.Defensive medicine among high-risk specialist physicians in a volatile malpractice environment. The Journal of the American Medical Association; 2005 Jun 1;293(21):2609-17.

5. Can İ Ö, Özkara E, Can M. Yargitayda Karara Bağlanan Tibbi Uygulama Hatası Dosyalarının Değerlendirilmesi, Dokuz Eylül Üniversitesi Tıp Fakültesi Dergisi, 2011, Cilt 25, Sayı 2, s: 69-76

6. Yilmaz A, Demiral G, Sahin G, Yener O, Kocatas A, Boluk S. The Impact of Turkish Penal Code (TPC) which entered into force in 2005 on surgeons.J For Med 2013;27(3):158-72 doi: 10.5505/adlitip.2013.42714
7. Pakiş I. Ölüm ya da ölü doğumla sonuçlanan tıbbi uygulama hatalarına yaklaşımda adli otopsinin rolü. M.Ü. Sağlık Bilimleri Enstitüsü, Doktora Tezi, İstanbul, 2006.

8. Budakoglu I, Karabacak O,, Coskun O, Karabacak N, Personality and Learning Styles of Final-Year Medical Students and the Impact of these Variables on Medical Specialty Choices, Gazi Medical Journal, 2014; 25:138-141

9. Tan M N, Özçakar N, Kartal M, Asistan Hekimlerin Tipta Uzmanlık Eğitimi Kapsamında Mesleki Memnuniyetleri ve Yaşam Koşulları ile İlişkisi, Marmara Medical Journal, 2012;25:20-5

10. Kaya, A., Aktürk, Z., Çayır, Y., Taştan, K., 2007-2013 Arası Tıpta Uzmanlık Sınavları: Bir Trend Analizi, Ankara Medical Journal, 2014, Cilt 14, Say12, s53-58 